\title{
Thin Edge-Defined Film-Fed Growth (EFG) Octagons
}

\section{Final Subcontract Report 14 February 1991 - 18 May 1991}

NREL technical monitor: R. Mitchell

J. P. Kalejs

Mobil Solar Energy Corporation Billerica, Massachusetts

National Renewable Energy Laboratory (formerly the Solar Energy Research Institute) 1617 Cole Boulevard Golden, Colorado 80401-3393

A Division of Midwest Research Institute Operated for the U.S. Department of Energy under Contract No. DE-AC02-83CH10093

Prepared under Subcontract No. XC-1-10057-12 March 1992 


\title{
On September 16, 1991 the Solar Energy Institute was designated a national laboratory, and its name was changed to the National Renewable Energy Laboratory.
}

\section{NOTICE}

This report was prepared as an account of work sponsored by an agency of the United States government. Neither the United States government nor any agency thereof, nor any of their employees, makes any warranty, express or implied, or assumes any legal liability or responsibility for the accuracy, completeness, or usefulness of any information, apparatus, product, or process disclosed, or represents that its use would not infringe privately owned rights. Reference herein to any specific commercial product, process, or service by trade name, trademark, manufacturer, or otherwise does not necessarily constitute or imply its endorsement, recommendation, or favoring by the United States government or any agency thereof. The views and opinions of authors expressed herein do not necessarily state or reflect those of the United States government or any agency thereof.

\author{
Printed in the United States of America \\ Available from: \\ National Technical Information Service \\ U.S. Department of Commerce \\ 5285 Port Royal Road \\ Springtield, VA 22161
}

Price: Microfiche A01

Printed Copy AO3

Codes are used for pricing all publications. The code is determined by the number of pages in the publication. Information pertaining to the pricing codes can be found in the current issue of the following publications which are generally available in most libraries: Energy Research Abstracts (ERA); Government Reports Announcements and Index (GRA and I); Scientific and Technical Abstract Reports (STAR); and publication NTIS-PR-360 available from NTIS at the above address. 


\section{DISCLAIMER}

Portions of this document may be illegible electronic image products. Images are produced from the best available original document. 


\section{TABLE OF CONTENTS}

$\begin{array}{lll}1.0 & \text { Objective } & 1\end{array}$

$2.0 \quad$ Background

3.0 Scope of Work 2

3.1 Mobil Solar EFG Technology Processes 2

3.2 Proposed EFG Wafer Manufacturing 3 Improvements/Benefits

3.3 Problem Identification 5

3.4 Problem Solution/Program Plans 7

$\begin{array}{lll}4.0 & \text { Program Plan } & 10\end{array}$

$\begin{array}{ll}\text { Appendix 1 } & 12\end{array}$ 


\section{THIN EFG OCTAGONS}

\subsection{Objective}

Phase I of this subcontract was initiated at Mobil Solar Energy Corporation (MSEC) on February 19, 1991. Its objective was to identify: 1) current capabilities in manufacturing technology for 200 micron thick $10 \mathrm{~cm} \times 10 \mathrm{~cm}$ crystalline silicon wafers produced by growth of octagons by the Edge-defined Film-fed Growth (EFG) technique and laser cutting of these octagons into wafers, 2) potential manufacturing improvements resulting from the decrease of the thickness of the EFG octagon and increases in laser cut edge quality and in cutting speed that lead to significantly reduced manufacturing costs, improved performance and increased production capacities, 3 ) problems impeding the achievement of these potentials, and 4) costs and other requirements involved in overcoming the problems.

\subsection{Background}

The work carried out at MSEC under Phase I of this subcontract consisted of the formulation of a program and of the time- and cost-estimates for the commercial development of an EFG manufacturing technology for production of 200 micron thick 10 $\mathrm{cm} \times 10 \mathrm{~cm}$ area crystalline silicon wafers. These improvements, when implemented, advance Mobil Solar's potential for achieving competitiveness within the PV industry and open up new possibilities for its entry with EFG material into world markets for polycrystalline silicon wafers.

The program has the following technical objectives for improving MSEC's manufacturing technology for EFG wafers:

(i) to decrease the EFG octagon and wafer thickness from the current 400 microns to 200 microns;

(ii) to decrease damage in laser cutting of EFG wafers and to improve wafer edge strength thus raising mechanical yields; to increase the laser cutting rates from about $2.5 \mathrm{~cm} / \mathrm{s}$ to over $7.5 \mathrm{~cm} / \mathrm{s}$ while at the same time maintaining high cutting yields and improving the strength of the cut wafer;

(iii) to improve process control and wafer productivity by implementing new Intelligent Processing of Materials (IPM) control strategies and on-line material property monitoring.

The reduction in thickness represents a 50\% decrease in silicon material utilization with respect to current practice. Silicon is the largest cost component of low-cost terrestrial photovoltaic modules. Significant cost savings can be additionally realized from improved performance if the mechanical yield of the thinner octagons is increased by increasing the wafer edge strength. Increasing the laser speed and raising the throughput offers the potential for a significant reduction in the wafer manufacturing cost component contributed by the laser cutting process. Thus, if the thin octagon can be cut at the high speeds, while a substantial reduction in mechanical (breakage) losses is achieved through improving cut wafer edge strength at the same time, the full benefits of the potential improvements in EFG wafer manufacturing technology proposed here can be realized. Improved controls of the EFG growth process and on-line monitoring of thin EFG octagon properties will be used to design new equipment to improve yields and productivity in the crystal growth area. 


\subsection{Scope of Work}

The following sections describe the scope of the work for the MSEC proposal for participation in Phase II of the PVMaT project. This includes a description of the MSEC process sequence, the changes in the existing wafer production processes that are envisioned to reduce manufacturing costs and improve throughput, problem areas that may impede achievement of potential benefits, approaches which may be taken for solution of these problems, and associated time and cost-estimates.

\subsection{Mobil Solar EFG Technology Processes}

This section describes Mobil Solar's current technological status. Mobil Solar has been directing its technology development efforts for the past three years at identifying and demonstrating a unique manufacturing process sequence that it believes will produce PV modules at the low costs required to profitably sell into the early grid-connected U.S. utility market. At the core of this Mobil Solar PV technology is the proprietary Edge-defined Film-fed Growth (EFG) process for producing crystalline silicon sheet in the form of octagons. This proposal will address manufacturing improvements in the growth and laser cutting of EFG octagons that would lead to lower costs and increased production capacities of nominal $10 \mathrm{~cm}$ square $\mathrm{EFG}$ wafers.

The process sequence that takes EFG material from growth to full area solar cells which is currently envisioned consists of the following steps:

Crystal Growth

Mobil Solar produces hollow octagon tubes of sheet silicon consisting of eight-sided tubes with each side $10 \mathrm{~cm}$ wide. These tubes are grown in lengths of about 5 meters, with continuous melt replenishment, and with 10 to 20 tubes produced per crystal growth set-up.

\section{Laser Cutting}

The octagon tubes are cut into wafers approximately $10 \mathrm{~cm}$ square using lasers. Very high cutting yields (greater than 95\%) and overall silicon material utilization are obtained at this step. This preserves the inherent advantage of the sheet silicon technology by avoiding the kerf losses involved in bulk melt growth (CZ and FZ) and ingot (casting) crystalline silicon technologies.

Cell Processing

The conversion of EFG silicon wafers into solar cells is accomplished using a proprietary sequence of processes that are specifically designed to:

- minimize the number of process steps required;

- approach continuous processing as closely as possible;

- minimize the amount of wet processing and the number of wet to dry transitions;

- maximize in-plant safety and minimize environmental impact by eliminating toxic gases and limiting the use of acid;

- minimize sensitivity to process variables, i.e., be "robust";

- be as gentle as possible, avoiding contact with the wafer whenever possible;

- utilize materials, processes, and conditions that are inherently inexpensive; and 
- be capable of producing high efficiency solar cells

from the unique EFG material.

In terms of function, the steps are:

Junction Formation

Antireflection Coating

Front Metallization

Back Metallization

Material Upgrading.

To date, this process and its predecessors have demonstrated the ability to produce yields sufficient to support commercial production cost objectives, and cell efficiencies as high as $15 \%$ on $100 \mathrm{~cm}^{2}$ area solar cells - all using commercially practicable technologies.

Equipment

Growth furnaces manufactured locally according to MSEC specifications. Furnaces are inexpensive relative to other crystal growth systems, and display very high areal growth rates (exceeding $150 \mathrm{~cm}^{2} / \mathrm{min}$ ) with continuous melt replenishment. Growth initiation and furnace thermal control are computer controlled.

Lasers with auto focus.

Material electronic characterization using Photoconductivity Decay Lifetime and spectral response.

Cambridge Instruments SEM (EBIC and general microscopy).

Oriel solar simulator, MSEC modified (cell efficiency).

Nicolet IR spectrophotometer (impurity measurement and film characterization) with low temperature stage.

Perkin-Elmer UV visible spectrophotometer (surface reflectance)

Belt furnace with a 24 in. wide belt.

MSEC specified equipment for applying front and back metallization.

Low power laser for scribing silicon.

In-house designed and built automated cell-to-cell interconnect unit.

Two large area laminators capable of manufacturing 4 foot $x 6$ foot panels.

In-house designed and built high-potential test unit.

Computer controlled Xenon pulse solar simulator with high speed data acquisition hardware and software for product characterization.

In-house reliability testing apparatus for predicting field performance. 


\subsection{Proposed EFG Wafer Manufacturing Improvements/Benefit}

\section{Improvements}

The proposal to improve the EFG manufacturing process addresses means to lower costs associated with three integral parts of the Mobil Solar EFG silicon wafer production process: silicon material cost (direct materials) wafer mechanical integrity (yield), and laser cutting (throughput).

Silicon charge material constitutes the largest single cost component in the manufacturing of low-cost terrestrial PV modules. The first change in the EFG wafer manufacturing process proposed above - to lower octagon tube thickness by a factor of two - decreases the silicon material utilization nearly proportionately. A 400 micron thick $10 \mathrm{~cm} \times 10 \mathrm{~cm}$ wafer contains 9.2 grams of silicon, so that growth at 200 microns reduces the silicon material usage by 4.6 grams per wafer. At a silicon raw material cost of $\$ 40 / \mathrm{kg}$, this results in a cost savings of about 18 cents per wafer. The percentage contribution of this silicon material reduction in lowering the direct manufacturing cost of the wafer becomes increasingly more significant as other (non-silicon) manufacturing costs are decreased as may be anticipated in the large volume low cost terrestrial wafer production line envisioned for future EFG technology.

A lower EFG wafer manufacturing cost associated with silicon material savings cannot be realized unless mechanical yields (i.e., those attributed to breakage of the wafer) are maintained as EFG tube thickness is decreased. Losses arise in processing of grown sheet and wafers into solar cells. EFG wafer resistance to fracture after cutting is limited by laser-induced damage in the wafer edge. Laser cutting parameters as well as tube handling mechanisms affect the extent of the damage. The degree to which this will happen and the extent to which these cutting conditions and variables need to be modified as octagon thickness is decreased to target levels is largely unknown.

It is proposed as part of this submission that new laser cutting configurations be developed and tested to attempt to eliminate wafer damage arising in cutting. This requires decreasing the microcrack length drastically or, most preferably, eliminating them altogether. The cutting and mechanical yield improvements in the cell processing line that may be realized in eliminating entirely edge microcracks induced by laser cutting, for example, could at their best provide a cost reduction comparable to that obtained from the proposed silicon material savings.

Laser and tube handling equipment capital costs incurred at the laser cutting rates currently practiced represent a substantial contribution to EFG wafer cost. The throughput rate at the laser cutting station can be significantly increased with respect to the present EFG process performance if the cutting is carried out with the factor of three and greater laser cutting speed proposed for this program. It is imperative that such improvements are achieved without compromising wafer mechanical strength and yields at the target thickness of 200 microns, as noted above.

Finally, process control improvements will be targeted through work on implementing new control strategies for EFG octagon growth and material property on-line monitoring. This will raise the productivity in crystal growth and the yield of useful wafers and help reduce overall costs of their manufacture.

Long Range Benefits 
Long range benefits arising from implementation of the proposed improvements in Mobil Solar's EFG wafer production technology are far-reaching. These benefits encompass both the potential for Mobil Solar to more readily commercialize its PV modules and products and its ability to enter world markets for sale of polysilicon wafers in a favorable competitive position.

With respect to the first of these benefits, a decreased utilization of silicon material results in a decrease in the sensitivity of EFG wafer and PV module manufacturing technology to availability of and increases in the cost of silicon charge material. The decreased silicon material content of thinner EFG wafers also proportionately reduce demand for raw silicon (charge material). The decrease in consumption of silicon in future PV markets will run into the thousands of tons at the projected multi-gigawatt sales of PV products expected to materialize in the long term.

At present, the market price of suitable silicon charge material for polycrystalline PV products is not controlled by factors indigenous to the PV industry. Supply and demand fluctuate, dependent upon the fortunes of the semiconductor industry. This situation acts as a deterrent to and adds uncertainty in planning of scaling up volume in the fledgling U.S. PV industry targeted at power modules of chief interest to Mobil Solar. This U.S. industry is currently almost entirely based on crystalline silicon products, and is expected to remain so during the initial years of expansion of the power module segment of the PV industry.

The world market for polysilicon wafers is at present very unsettled. It is dominated by a single overseas source and wafer prices are consequently not greatly driven by competition. Current $10 \mathrm{~cm} \times 10 \mathrm{~cm}$ wafer prices in world markets range upwards from about $\$ 3.00$ for quality polycrystalline silicon wafers. Suppliers of this material in wafer form are few in number and are located outside of the United States. Both price and availability are currently acting as deterrents to a rapid expansion of PV products based on polycrystalline silicon wafers. Success of the proposed MSEC program for reducing EFG wafer manufacturing costs will impact on this situation very positively. The direct manufacturing cost for a thin EFG wafer, after full implementation of the proposed cost reductions, is projected to fall within a factor of two to three below current world market prices for comparable quality polysilicon material. Thus, introduction of EFG wafers as a competitive source of polysilicon wafers would stimulate U.S. PV product manufacture and encourage development of new PV export markets with a wide range of polysilicon material-based applications.

\subsection{Problem Identification}

This section identifies and describes the problems that need to be solved to achieve implementation of an improved EFG manufacturing technology for producing low cost 200 micron thick wafers. They are to be addressed with subtasks in three general technical areas: furnace development for improvement of growth process control and of thickness uniformity, stress control and laser cutting.

Furnace Development. Thickness variations around the perimeter of the 400 micron thick EFG octagon tubes produced with current MSEC technology cannot be tolerated when tube wall thickness is reduced to 200 microns. They impact first on the ability to control growth of the octagon. They interfere with reproducible and successful growth initiation, and prevent achievement of the long periods of stable growth needed for continuous growth of a $6 \mathrm{~m}$ long tube. Extreme thickness nonuniformity additionally impacts on yield in cutting and handling of wafers. A number of interactive factors are known to produce detrimental thickness nonuniformity - die and crucible design, induced heat and temperature variations due to geometrical factors and furnace construction material 
inhomogeneities, magnetic field forces and growth ambient effects related to levels of contaminant impurities. Improved sensors for measuring growth variables and automated systems for their control are needed to guide these studies. These will help to identify interactive aspects involving these variables and lead to development of strategies that can control growth at the levels required for a production prototype furnace. Some material quality characterization with structure and lifetime measurements will be carried out in this subtask. Its purpose will be to ascertain that the changes made in furnace redesign and growth variables in order to obtain the thinner octagon do not adversely impact the ability of the EFG material to make high quality solar cells. This subtask will culminate with construction and testing of a furnace which will incorporate improvements in thickness control and uniformity into a new prototype EFG system capable of growth of 200 micron tubes. At the same time, other productivity aspects need to be maintained, at the least, at current EFG technology levels: tubes up to $6 \mathrm{~m}$ lengths, with minimal growth interruption (less than one freeze or meniscus failure per tube), and with continuous melt replenishment.

Stress Control. As the thickness of EFG octagons is decreased, control of flatness and residual stress becomes an increasing problem due to thermoelastic stress which is inherent to the process of cooling the tube from the silicon melting point of $1412 \mathrm{C}$ to room temperature. This stress needs to be reduced from present levels because stress thresholds for buckling, i.e., out-of-plane deformation of the octagon face, decrease as thickness is decreased. At the same time, residual stress also needs to be minimized in order to ensure that the material will not fracture during cutting and be strong enough to survive with high yields during subsequent handling in cell processing. Residual stress is the stress which remains in the material after cooling to room temperature. It originates from dislocations generated as a result of plastic deformation in the octagon because it is grown at high speeds and with large nonlinear temperature gradients. Advances both in theoretical understanding of means to control stress and development of improved furnace configurations to produce lower stress crystals are needed in order to allow design of an EFG manufacturing unit for production of 200 micron thick octagons of acceptable mechanical properties.

Laser Cutting. The measure of success of the EFG octagon technology for producing thin wafers is defined by laser cutting yields and the strength of the $10 \mathrm{~cm} \times 10 \mathrm{~cm}$ wafer obtained after the cutting process. A number of factors interact to adversely influence the output of the laser cutting step as thickness is decreased and higher laser cutting speed are imposed. Local stress is generated by the laser during the cooling of the sample edge after cutting, and this produces microcracks which limit the strength of the wafer. At the same time, microcrack formation is affected by residual stress arising during the crystal growth process. The minimization of laser damage and residual stress needs to be addressed in an interactive and iterative manner with the above subtask on stress control. Laser beam conditions and operating power levels further affect microcrack formation. In order to achieve the desired increases in laser cutting speed from $2.5 \mathrm{~cm} / \mathrm{s}$ to over $7.5 \mathrm{~cm} / \mathrm{s}$, it will be necessary to use new designs of lasers which have not been previously been utilized to cut EFG material. The impact of new laser beam conditions and interaction with material variables is not known and will need to be studied both at a theoretical and experimental level to accelerate progress. Finally, improved laser cutting technology needs to be integrated with proprietary MSEC octagon tube handling and cutting fixturing which manipulate the tube and the wafer during the cutting process. This phase of wafer production is particularly sensitive to material thickness. Effects from octagon thickness changes need to be evaluated in the MSEC on-line pilot production setting in order to ensure that the benefits of improved cutting conditions and a faster laser speed are passed on in acceptable wafer strength, cutting station yield and throughput, that allow wafer cost reductions to be realized. 
Process Control and Material Specification. The subtasks in this section of the program will focus on developing a new generation of ssnsors to monitor the EFG growth process. These will be integrated using Intelligent Processing of Materials (IPM) concepts and evaluated for their ability to produce cost-effective improvements in the growth of thin octagons.

Generic problems which will be addressed in the course of this work are:

- $\quad$ identification and development of means to control magnetic field and induced power effects (heating, forces) on silicon melt during melt crystal growth;

- development of crystal growth control strategies utilizing Intelligent Processing of Materials (IPM) concepts;

- $\quad$ identification and reduction of the deleterious effects of carbon, oxygen and nitrogen impurities on structural, geometrical and mechanical properties of sheet silicon;

- definition and minimization of effects of inelastic (creep, plastic flow) stressgenerating processes on flatness and residual stress in silicon sheet crystal growth;

- understanding of laser beam-material interactions for purposes of reducing cutting damage and maximizing silicon wafer edge strength.

\subsection{Problem Solution/Program Plans}

The program proposed to obtain solutions to the above problems is outlined in the attached work breakdown structure and time schedule. This program will span three years, and requires an overall funding level in the range from $\$ 7.5$ to $\$ 8.5 \mathrm{MM}$, with the higher level to include development of intelligent processing strategies for controlling crystal growth. The staffing level from MSEC is estimated to be about 11 full time personnel.

MSEC will enter into cost sharing in a number of areas. This will include but not necessarily be limited to: all facilities and their maintenance; two fully functioning EFG octagon crystal growth stations; an integrated tube handling and laser cutting station; material evaluation and characterization facilities; in-house state-of-the-art commercial finite element analysis capabilities utilizing COSMOS and ANSYS; finite element magnetic and thermal field models of the EFG furnace developed previously at MSEC expense; and several university and industrial consultants who have already been working with MSEC over a number of years and acquired extensive experience in many aspects of EFG technology.

Two workshops were held at MSEC during the Phase I subcontract period to identify consultants who could aid in developing strategies and program plans in two crucial areas. These were entitled "Stress Analysis for Thin EFG Octagons" and "Automatic Controls and Intelligent Processing of Materials (IPM) for Thin EFG Octagons". The workshop agendas and the curriculum vitae of consultants committed to participate in the MSEC proposal are given in Appendix 1. There have also been follow-up supplementary discussion with consultants to develop program plan details.

Consultant participation in the proposed program are identified below. An emphasis has been given to dealing with consultants located at universities within the continental U.S. Most have additionally had previous extensive exposure to the problems facing crystal growth system development for PV industry materials. Discussions with several other consultants are continuing. Several main subcontractors have been identified to do equipment design and engineering for development of crystal growth equipment and for lasers. A search is under way for alternative equipment manufacturers as back up vendors. They will not be engaged until the construction phase in the latter part of the program. 
Several industrial experts have been contacted to help in sensor development and planning and implementation of Intelligent Processing of Materials (IPM) capabilities in crystal growth. IPM strategy allows going beyond the conventional control algorithms (e.g., for temperature) to directly include desired materials properties, such as flatness, thickness and electronic quality for on-line measurement and control. Implementation of IPM eliminates production of crystal not within target specifications of material parameters directly at the growth furnace, and thus increase productivity. IPM success requires development of a new generation of sensors. For EFG octagons, this includes sensors for on-line temperature measurements in the growing crystal, and on-line monitors of flatness, of thickness and ambient conditions. Such sensors then become the basis of expanded control strategies which incorporate a simulator concept, which ties models for desired material behavior to the crystal unit production parameters being measured and controlled.

A summary of the approaches to be taken, and resources external to MSEC that have been identified to help in solving the problems in each of the three main technical subtask areas is given next.

\section{Task 1: Thin Octagon Growth \\ The goal of this subtask is to design, build and test the EFG crystal growth furnace for production of octagons that will be the basis of a manufacturing technology for 200 micron thick $10 \mathrm{~cm} \times 10 \mathrm{~cm}$ EFG wafers. Two EFG octagon growth stations already operative at MSEC facilities will be cost shared for the first and second years of the subtask to carry out the research and evaluate the new designs, operating conditions and possible configuration of the production prototype. Final design criteria and cost effectiveness studies of the proposed improvements will be completed by the end of the second year. The program in the first half of the third year will consist of the design and fabrication of the prototype. It will culminate with six months of testing of the integrated design improvements at a pilot production level of operation.}

Research oriented experimentation with two existing EFG furnaces at MSEC will be carried out at the start up of the program until new designs of components specifically aimed at solving the identified problems standing in the way of thin octagon growth become available. In the second half of the first year, conversion of the furnaces take place to test advanced concepts that evolve from a parallel theoretical efforts studying fundamental design parameters. The theoretical efforts will be closely integrated with work on sensor development to improve monitoring capabilities for crystal growth variables that need to be better understood in order to allow design of an improved growth system that targets $\mathbf{2 0 0}$ micron thick octagons. External resources that will be used to support this subtask are:

- $\quad$ Professor Robert Brown of MIT to develop simulator concepts and control logic for automatic control loops for an IPM strategy;

- Dr. Mike Wargo of MIT to consult on thermal sensor development elements for IPM of EFG octagons;

- $\quad$ EOIS corporation to develop on-line flatness monitoring technology for IPM;
MacNeal-Schwendler consultants on magnetic and thermal modelling of EFG systems using their NASTRAN and EMASS computer codes. This will involve both $2-d$ combined thermal and magnetic EFG models already developed at MSEC, and a 3-d magnetic simulation;

- $\quad$ Crystalox Ltd, to provide design engineering support for crystal growth equipment development. 
One in-house EFG octagon furnace will carry out an experimental program to support theoretical studies and to identify factors that produce stress and buckling as tube wall thickness is decreased, and to reduce their deleterious effects in 200 micron thick material. The experimental program will be integrated with theoretical studies of stress generating mechanisms, which will use both in-house computing and rented magnetic and thermal computer codes, and university consultants. Experimental characterization of stress through stress measurements and flatness monitoring will also be used to guide this work. External resources that will be used in support of this subtask:

- $\quad$ Professor John Hutchinson of Harvard University to consult on stress analysis;

- $\quad$ Professor Peter Mataga of the University of Florida to consult and carry out a program on calculation of inelastic effects (creep, plastic flow)) in stress generation in sheet crystal growth;

- $\quad$ Professor Oscar Dillon of the University of Kentucky to consult on buckling;

- $\quad$ Professor Steven Danyluk of the University of Illinois (Chicago) to consult on and carry out stress measurements;

- $\quad$ EOIS Corporation to develop on-line buckle measurement techniques for crystal growth process monitoring;

\section{Task 2 Laser Cutting}

The initial work on laser development, spanning the first two years, will be carried out at subcontractor facilities to achieve two objectives: first, to demonstrate conditions of laser cutting that produce lower damage and/or eliminate microcracks, so that an increased strength EFG wafers is obtained; second, to implement the solutions in a high speed laser cutting system that can operate at cutting speeds of $7.5 \mathrm{~cm} / \mathrm{s}$ or greater. During this time support of this work will be provided to the laser subcontractors in supplying EFG samples from the crystal growth process development subtasks, in characterization of the cut quality, in theoretical studies of the cutting process, and in evaluation of the wafer resistance to fracture. The latter work will be done in conjunction with a university consultant specializing in mechanical properties of silicon. Two laser systems will be evaluated in the first two years of this subtask. Toward the end of the second year, one of these will be chosen for prototype testing. The laser and beam handling configurations that result from this development phase will be supervised to ensure the laser beam conditioning and beam delivery designs are completely compatible with the MSEC inhouse proprietary cutting station. The work in the last year of the subtask will consist of two activities: reconfiguration of the research laser so that it meets with the specifications of the pilot line operation at MSEC; then integration of the improved design laser with MSEC tube handling fixturing and testing of the system in cutting 200 micron octagon tubes in an on-line setting at MSEC facilities.

The external resources that will be used to support this subtask are:

- Professor Todd Gross of the University of New Hampshire to consult on the lasersilicon material interactions: through theoretical analysis of the laser cutting process and measurement services on cutting damage;

- $\quad$ Lasag Ltd and Plasmatronic Inc. to carry out development of reduced damage and increased cutting speed lasers and integrate them with MSEC process requirements. 


\section{Task 3: Sensor Development and Product Specification}

Sensors to measure the temperature distribution around the interface, local thickness distribution of the octagon, and the shape of the buckles are needed to accomplish the goals of Task 1 . These sensors, initially used to monitor the progress in the initial stages of the program, will form an integral part of the Intelligent Processing of Materials (IPM) concept. IPM control strategy for EFG material will enhance the productivity of the process by on-line quality control. Specifically, the senors developed to measure the thickness and the buckles during growth will be integrated with mechanisms that change the circumferential thickness (coil positioning mechanism) and the interface temperature field (position of the main coil, the outside afterheater and the current through the auxilary coil). The sensor development work will be carried out by consultants who are experts in their fields. Integration work will be carried out by subcontractors in collaborationm with Mobil Solar personnel. This Task will also work to develop specifications for thin EFG wafers in the areas of thickness uniformity, flatness and stress, and monitor electrical charactersitics for purposes of maintaining high lifetimes in the as-grown wafers.

\subsection{Program Plan}

The outline on the next page gives the scheduling of the various subtasks discussed above for a proposed three year program. Subtask 4 on Program Management will support the above activities. The Program Manager will be Dr. Juris P. Kalejs. The Principal Investigator will be Dr. S. Rajendran. 
THIN EFG OCTAGONS - PHASE I

ESTIMATED WORK BREAKDOWN STRUCTURE AND PROGRAM PLAN

Subject

Task 1-

Thin Octagon Growth

Thermoelastic stress

Reduction

Task 2-

Laser Cutting

Task 3-

Process Control and

Product Specification

Task 4-

\section{Description}

EFG octagon system No. 1

Thickness uniformity

optimization at 200 microns

EFG octagon system No. 2

- design and construction

- testing of new concepts

Model construction,

evaluation and application

Thin material stress

reduction program

EFG factory prototype

design, construction and

testing

Reduced damage

capability evaluation and

development

High speed laser development

200 micron octagon on-1ine cutting tests

Sensor Development

Control Strategy Development

Product Specification

Program Management 1st Year 2nd Year 3rd Year

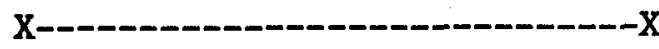

X-- - - - - - -

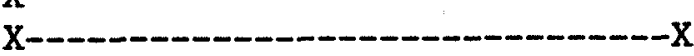

X-------------X

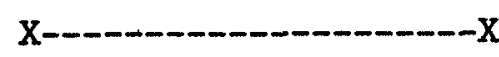

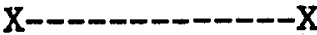

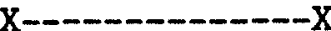

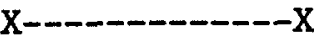

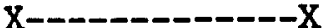

X-----------------X

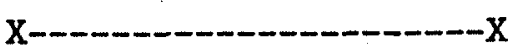

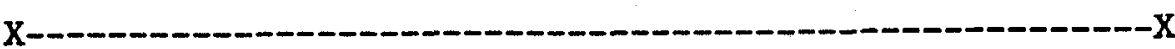

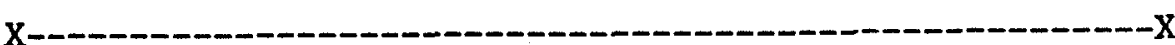




\title{
Appendix 1
}

\begin{abstract}
Agenda for workshops on "Stress Analysis for Thin EFG Octagons" and "Automatic Controls and Intelligent Processing of Materials (IPM) for Thin EFG Octagons" held at Mobil Solar during Phase I of this subcontract.
\end{abstract}




\title{
Mobil Solar Energy Corporation
}

\author{
Agenda \\ Seminar on Stress Analysis \\ on \\ Thin EFG Octagons
}

Mobil Solar Energy Corporation

4 Suburban Park Drive, Billerica, MA 01821

March 5, 1991

7:30-8:30 Breakfast at Stouffer's Inn, Bedford

8:30-9:00 Introduction and tour of Mobil Solar

9:00-10:15 Mobil Solar presentations

Break

10:30-12:00 Round table discussions:

Professor John Hutchinson, Harvard University Professor Oscar Dillon, University of Kentucky Professor Todd Gross, University of New Hampshire Mobil Solar Personnel

12:00-1:30 Wrap-up luncheon 


\title{
Agenda
}

\author{
Workshop on Automatic Controls
}

and

Intelligent Processing of Materials (IPM)

for

Thin EFG Octagons

Mobil Solar Energy Corporation

4 Suburban Park Drive, Billerica, MA 01821

March 20, 1991

9:00-10:00 Preliminary Discussions

10:00-10:30 Mobil Solar Presentation

10:30-11:30 Round Table Discussions

Professor R.A. Brown, MIT

Dr. M. Wargo, MIT

Mobil Solar Personnel

11:45-1:00 Lunch and Wrap-up Discussions 


\begin{tabular}{|c|c|c|c|}
\hline $\begin{array}{c}\text { Document Control } \\
\text { Page }\end{array}$ & $\begin{array}{l}\text { 1. SERI Report No. } \\
\text { NREL/TP-214-4484 }\end{array}$ & $\begin{array}{l}\text { 2. NTIS Accession No. } \\
\text { DE92001167 }\end{array}$ & 3. Recipient's Accession No. \\
\hline \multirow{2}{*}{\multicolumn{3}{|c|}{$\begin{array}{l}\text { 4. Title and Subtitle } \\
\text { Thin Edge-Defined Film-Fed Growth (EFG) Octagons }\end{array}$}} & $\begin{array}{l}\text { 5. Publication Date } \\
\text { March } 1992 \\
\end{array}$ \\
\hline & & & 6. \\
\hline \multicolumn{3}{|l|}{$\begin{array}{l}\text { 7. Author(s) } \\
\text { J.P. Kalejs }\end{array}$} & 8. Performing Organization Rept. No. \\
\hline \multirow{2}{*}{\multicolumn{3}{|c|}{$\begin{array}{l}\text { 9. Performing Organization Name and Address } \\
\text { Mobil Solar Energy Corp. } \\
4 \text { Suburban Park Dr. } \\
\text { Billerica, MA } 01821\end{array}$}} & $\begin{array}{l}\text { 10. Project/TaskWork Unit No. } \\
\text { PV250101 }\end{array}$ \\
\hline & & & $\begin{array}{l}\text { 11. Contract (C) or Grant (G) No. } \\
\text { (C) XC-1-10057-12 } \\
\text { (G) }\end{array}$ \\
\hline \multirow{2}{*}{\multicolumn{3}{|c|}{$\begin{array}{l}\text { 12. Sponsoring Organization Name and Address } \\
\text { National Renewable Energy Laboratory } \\
1617 \text { Cole Blvd. } \\
\text { Golden, CO } 80401-3393\end{array}$}} & $\begin{array}{l}\text { 13. Type of Report \& Period Covered } \\
\text { Technical Report } \\
\text { 14 February } 1991 \text { - } 18 \text { May } 1991 \\
\end{array}$ \\
\hline & & & 14. \\
\hline \multicolumn{4}{|c|}{$\begin{array}{l}\text { 15. Supplementary Notes } \\
\text { NREL technical monitor: R. Mitchell }\end{array}$} \\
\hline \multicolumn{4}{|c|}{$\begin{array}{l}\text { Mobil Solar Energy Corp. investigated manufacturing crystalline silicon wafers using the edge-defined film-fed growth (EFG) } \\
\text { technique. This report identifies the following: (1) current capabilities for manufacturing } 200 \text {-micron-thick crystalline silicon } \\
\text { wafers }(10 \mathrm{~cm} \times 10 \mathrm{~cm} \text { ) produced by growing octagons using the EFG technique and laser cutting them into wafers; } \\
\text { (2) potential manufacturing improvements from decreasing the thickness of the wafers, improving the quality of the laser cut } \\
\text { edge, and increasing cutting speed, all of which lead to reduced manufacturing costs, improved performance, and increased } \\
\text { production capacities; (3) problems that impede achieving these potentials; and (4) costs and other requirements involved in } \\
\text { overcoming the problems. }\end{array}$} \\
\hline \multicolumn{4}{|c|}{$\begin{array}{l}\text { 17. Document Analysis } \\
\text { a. Descriptors } \\
\text { wafer manufacturing; cost-effecti } \\
\text { octagon wafers ; photovoltaics } \\
\text { b. Identifiers/Open-Ended Terms }\end{array}$} \\
\hline \multirow{2}{*}{\multicolumn{2}{|c|}{$\begin{array}{l}\text { 18. Availability Statement } \\
\text { National Technical Information Service } \\
\text { U.S. Department of Commerce } \\
\text { 5285 Port Royal Road } \\
\text { Springfield, VA } 22161\end{array}$}} & & $\begin{array}{l}\text { 19. No. of Pages } \\
19\end{array}$ \\
\hline & & & $\begin{array}{l}\text { 20. Price } \\
\mathrm{A03}\end{array}$ \\
\hline
\end{tabular}

